\title{
METODOLOGIAS ATIVAS NO ENSINO DE GEOGRAFIA: UMA REVISÃO BIBLIOGRÁFICA SOBRE SEU USO NA EDUCAÇÃO PROFISSIONAL E TECNOLÓGICA
}

\author{
Fabiana Elayne Barros Damasceno ${ }^{1}$ \\ Thiago Coelho Silveira ${ }^{2}$ \\ Keylla Cristina Coelho Lima ${ }^{3}$ \\ Ivesmary Loureiro Ribeiro Magalhães ${ }^{4}$ \\ Rebecca Loureiro Ribeiro Magalhães ${ }^{5}$
}

RESUMO: O presente artigo trata de uma revisão bibliográfica analisa como o uso das Metodologias Ativas, no ensino da Geografia na Educação Profissional e Tecnológica/EPT, contribuem para a formação intelectual do discente e como essas metodologias podem desenvolver a autonomia do estudante, estimular a criatividade e o preparar para a tomada de decisões no contexto em que ele vive. Portanto, a revisão bibliográfica abordará as contribuições que as metodologias ativas trazem para o ensino da Geografia na Educação Profissional e Tecnológica, enquanto um recurso didático para uma formação crítica e reflexiva do estudante. Além disso, será discutido sobre as metodologias ativas utilizadas no processo de ensino e aprendizagem e que correntes do pensamento geográfico convergem para o emprego das metodologias ativas no ensino da geografia na EPT, para que, por fim, seja apontado como estas, podem contribuir para formação intelectual do discente. Para isso, foi realizada uma revisão bibliográfica sobre o objeto de estudo, partindo da leitura sistemática de artigos científicos publicados e selecionados por meio das bases de dados Google Acadêmico, SCIELO, períodicos, com o resumo e fichamento de cada obra, ressaltando os pontos abordados pelos autores pertinentes ao assunto em questão.

Palavras-chave: Ensino. Geografia. Metodologias Ativas. Educação Profissional e Tecnológica.

\footnotetext{
${ }^{\mathrm{I}}$ Mestranda do mestrado profissional PROFEPT-IFMA, Especialista em Engenharia Ambiental, em Docência do Ensino Superior e em Mediação de Conflitos e Arbitragem pela faculdade Unyleya. Graduada em Geografia Licenciatura pela Universidade Estadual do Maranhão (2010), em Geografia Bacharel pela Universidade Federal do Maranhão(UFMA) e em Direito pela FACEM-(Faculdade do estado do Maranhão).

${ }^{2}$ Doutor em História (UNISINOS). Professor do Instituto Federal do Maranhão (IFMA, Campus Presidente Dutra e do Programa de Pós-graduação em Educação Profissional e Tecnológica (ProfEPT/IFMA).

${ }^{3}$ Mestranda do mestrado profissional PROFEPT-IFMA, possui graduação em Letras e especialista na área de língua espanhola.

${ }^{4}$ Mestranda do mestrado profissional PROFEPT-IFMA, possui graduação em Tecnologia em Eletrônica Industrial e em Licenciatura em Pedagogia e especialização em Gestão Escolar;

${ }^{5}$ Especialista em Docência do ensino superior e bacharel em arquitetura e urbanismo.
} 
ABSTRACT: The present article is a literature review that analyzes how the use of Active Methodologies in the teaching of Geography in Professional and Technological Education/EPT contributes to the intellectual formation of the student and how these methodologies can develop student autonomy, stimulate creativity and prepare them to make decisions in the context in which they live. Therefore, the literature review will address the contributions that active methodologies bring to the teaching of Geography in Vocational and Technological Education, as a didactic resource for a critical and reflective training of the student. Moreover, it will be discussed about the active methodologies used in the teaching and learning process and which currents of geographic thought converge to the use of active methodologies in geography teaching in the VET, so that, finally, it will be pointed how these can contribute to the intellectual formation of the student. For this, a literature review was conducted on the object of study, starting with the systematic reading of scientific articles published and selected through the databases Google Academic, SCIELO, periodicals, with the summary and fiching of each work, highlighting the points addressed by the authors relevant to the subject in question.

Keywords: Teaching. Geography. Active Methodologies. Professional and Technological Education.

\section{INTRODUÇÃO}

Num sentido amplo, toda a aprendizagem é ativa em algum grau, porque exige do aprendiz e do docente formas diferentes de movimentação interna e externa, de motivação, seleção, interpretação, comparação, avaliação, aplicação. Aprendemos também de muitas maneiras, com diversas técnicas, procedimentos, mais ou menos eficazes para conseguir os objetivos desejados. Se queremos, enquanto docentes, que os alunos sejam proativos, precisamos adotar metodologias em que os alunos se envolvam em atividades cada vez mais complexas, em que tenham que tomar decisões e avaliar os resultados, com apoio de materiais relevantes. Se queremos que sejam criativos, eles precisam experimentar inúmeras novas possibilidades de mostrar sua iniciativa.

As escolas que nos mostram novos caminhos estão mudando para modelos mais centrados em aprender ativamente com problemas reais, desafios relevantes, jogos, atividades e leituras, valores fundamentais, combinando tempos individuais e tempos coletivos, projetos pessoais de vida e de aprendizagem e projetos em grupo. Isso exige uma mudança de configuração do currículo, da participação dos professores, da organização das atividades didáticas, da organização dos espaços e tempos pedagógicos.

Quanto mais aprendemos próximos da vida, melhor. Alguns teóricos enfatizam, há muito tempo, a importância de superar a educação bancária, tradicional e focar a 
aprendizagem no aluno, envolvendo-o, motivando-o e dialogando com ele. Os alunos aprendem melhor, quando os motivamos intimamente, quando eles acham sentido nas atividades que propomos, quando consultamos suas motivações profundas, quando se engajam em projetos em que trazem contribuições, quando há diálogo sobre as atividades e a forma de realizá-las.

Diante desse contexto estão as metodologias ativas, enquanto um dos caminhos a ser tomado pelo professor em sala de aula, no intuito de não apenas transmitir conhecimento, mas de promover contextos de participação do estudante na sua construção. Sabe-se que são métodos centrados no estudante e empregados como estratégias de ensino, as quais permitem explorar a aprendizagem do educando, instrumentalizando-o para resolução de problemas e para tornar-se argumentativo, pensante e colaborativo com/em grupo. Por meio delas o estudante vivencia o aprendizado e percebe aquilo que aprende, podendo assim participar inquietamente na construção do seu conhecimento. Portanto, entende-se que as metodologias ativas se configuram como um importante instrumento de empoderamento do estudante.

No ensino da Geografia na Educação Profissional e Tecnológica(EPT) busca-se a formação de estudantes preparados tecnicamente e intelectualmente, desenvolvendo competências profissionais capazes de se adaptar às mudanças do mundo de trabalho com agilidade, criatividade, proatividade e autoconhecimento e por meio das metodologias ativas efetivarão a aprendizagem significativa. Assim, é importante que o professor repense os processos de aprendizagem e a mediação do conhecimento com seus alunos, incorporando metodologias inovadoras ao processo de ensino, de modo a proporcionar a participação dos estudantes na construção do conhecimento.

Moran (2015) afirma que as metodologias ativas precisam complementar o método de ensino em sala de aula. Dito de outro modo, para que os estudantes sejam proativos e criativos, precisamos ser instigados estes no desenvolvimento de atividades mais complexas, em que tenham que tomar decisões e serem mais reflexivos. Segundo Bacich e Moran(2018), o estudante além de assumir uma postura participativa por meio das metodologias ativas, consegue resolver problemas, desenvolver projetos, criando oportunidades para agregar na sua construção do conhecimento. Ela enfatiza o papel 
protagonista do aluno, o seu envolvimento direto, participativo e reflexivo em todas as etapas do processo, experimentando, desenhando, criando, com orientação do professor (MORAN, 2017, p. oI).

Nesta direção, entende-se que nas metodologias ativas, “[...] o aprendizado ocorre a partir da antecipação, durante o curso, de problemas e situações reais, os mesmos que os alunos vivenciarão depois na vida profissional" (BACICH, 2015, p. 30). Logo, compreendese que as metodologias ativas, estão alicerçadas na autonomia, no protagonismo do aluno, onde o foco está no desenvolvimento de competências e habilidades, com base na aprendizagem colaborativa e na interdisciplinaridade, sendo estas características que constituem os princípios de atuação na EPT.

Os desafios aqui são relacionar a EPT com as mudanças organizacionais, com as inovações no meio tecnológico, com a ética, com a ecologia e dentro deste contexto a geografia estudará as relações humanas no espaço geográfico, nas competências que lhe cabem, colaborando na transposição desses desafios, visto que nela reside a responsabilidade em explicar fenômenos do cotidiano dos estudantes.

Reflexões da ordem de relações sociais, econômicas, ambientais e de produção do espaço, requerem a constituição de um ambiente de aprendizagem que faça sentido aos estudantes da EPT, tanto a nível profissional quanto pessoal. Para tanto, necessário se faz munir-se de estratégias facilitadoras, tais como - as metodologias ativas de ensino e aprendizagem - para que se fomente a sensibilização e tomadas de decisão dos discentes mediante os acontecimentos do seu dia a dia.

O ensino da Geografia embasado na utilização de diferentes recursos didáticos favorece aos discentes, maior compreensão sobre o espaço geográfico e a realidade base de suas vivências. A inserção da variedade de linguagens e diferentes métodos nas aulas torna a apreensão da ciência geográfica mais significativa na construção do conhecimento.

Diante disso, o presente trabalho tem por objetivo analisar as contribuições das metodologias ativas no ensino da geografia na EPT, enquanto um recurso didático para uma formação crítica e reflexiva do estudante, caracterizando as metodologias ativas utilizadas no processo de ensino e aprendizagem, refletindo sobre as correntes do pensamento geográfico que convergem para o emprego das metodologias ativas no ensino 
da geografia na EPT e apontando como estas, podem contribuir para formação intelectual do discente.

\section{METODOLOGIA}

O presente artigo trata-se de revisão bibliográfica sobre as Metodologias Ativas no ensino da Geografia na EPT e por isso, tem como base as pesquisas e as discussões de estudos escritos anteriormente sobre o tema. É a contribuição das teorias de outros autores para esta pesquisa. A pesquisa contou com a análise crítica de artigos científicos publicados e selecionados por meio das bases de dados Google Acadêmico, SciELO, ressaltando os pontos abordados pelos autores pertinentes ao assunto em questão.

Diante disso, foram analisados artigos em língua portuguesa e aqueles que envolvessem, especificamente, aplicação das metodologias ativas no ensino da geografia, em especial na educação profissional e tecnológica. Além disso, é importante destacar que as palavras-chave utilizados na busca das referências foram: "metodologias ativas", “ensino da geografia”, "educação profissional e tecnológica”, “ensino-aprendizagem”. Com isso, todos os estudos foram devidamente analisados, selecionados de acordo com o tema apresentado, título e conteúdo para a construção da revisão bibliográfica.

\section{AS METODOLOGIAS ATIVAS NO ENSINO DA GEOGRAFIA NA EDUCAÇÃO PROFISSIONAL E TECNOLÓGICA: DISCUSSÕES A PARTIR DA REVISÃO BIBLIOGRÁFICA}

Um dos grandes desafios da educação contemporânea é romper com a compreensão de currículo e avaliação tradicionais, engessados. Para isso, é necessário pensarmos de modo complexo, tendo em vista a dinâmica dos problemas da sociedade. Destaca-se que a educação do futuro pede uma reforma de mentalidades, pois, vai exigir um esforço transdisciplinar que seja capaz de rejuntar ciências e humanidades e romper a oposição entre natureza e cultura, visando à perspectiva da integralidade.

No relatório da Comissão Internacional sobre Educação para o século XXI editado pela UNESCO, Jacques Delors (1999) destaca que a educação deve organizar-se à volta de quatro aprendizagens fundamentais que serão os quatro pilares do conhecimento: aprender a conhecer, isto é, adquirir os instrumentos da compreensão; aprender a fazer, para poder agir sobre o meio envolvente; aprender a conviver, a fim de participar e cooperar com os 
outros em todas as atividades humanas e, finalmente, aprender a ser, via essencial que integra os três precedentes.

Dentro desse contexto, as metodologias ativas compreendem estratégias pedagógicas com eixo nos processos de ensino e aprendizagem do aprendiz, conduzindo a formação crítica de futuros profissionais, proporcionando o desenvolvimento de estudantes autônomos, criativos, críticos, interessados e firmes na tomada de decisões. Além da contribuição do educando as metodologias ativas também qualificam a prática docente do educador no seu planejamento. Podemos destacar que:

$\mathrm{O}$ ato de ensinar exige intervenções deliberadas para garantir que ocorram mudanças cognitivas no aluno. Portanto, os ingredientes-chave são estar consciente dos objetivos de aprendizagem, sabendo quando um aluno é bemsucedido em atingir aquelas metas; conhecer suficientemente a compreensão prévia dos alunos antes de cumprirem uma tarefa e conhecer o conteúdo a ponto de fornecer experiências significativas e desafiadoras a fim de que ocorra algum tipo de desenvolvimento progressivo. (HATTIE, 2017, p.I4).

Assim, segundo Camargo e $\operatorname{Daros}(2016)$, podemos destacar várias contribuições das metodologias ativas na vida dos estudantes e docentes na EPT, dentre elas: Desenvolvimento efetivo de competências para a vida profissional e pessoal; visão transdisciplinar do conhecimento; visão empreendedora; o protagonismo do aluno, colocando-o como sujeito da aprendizagem; o desenvolvimento de nova postura do professor, agora como facilitador, mediador; a geração de ideias e de conhecimento e a reflexão, em vez de memorização e reprodução de conhecimento.

Vários autores apresentam uma definição para metodologias ativas, porém o seu conceito vai sendo construído à medida que conhecemos as características de cada metodologia ativa.

João Mattar (2017, p. 21) concebe as metodologias ativas como "uma educação que pressuponha a atividade (ao contrário da passividade) por parte dos estudantes. Nesse sentido, a proposta do learning by doing (aprender fazendo) seria um exemplo de metodologia ativa".

José Moran (2018, p. 4) define metodologias como "grandes diretrizes que orientam os processos de ensino e aprendizagem e que se concretizam em estratégias, abordagens e técnicas concretas, específicas e diferenciadas". Ele afirma que "metodologias ativas são 
estratégias de ensino centradas na participação efetiva dos estudantes na construção do processo de aprendizagem, de forma flexível, interligada e híbrida”. Esta construção pode ser individual, grupal e tutorial - com a orientação de um mediador experiente.

Conforme Beto Silva (2018, p. 75), uma metodologia ativa "reconhece e potencializa a participação ativa e colaborativa e, desse modo, mobiliza para alterar percursos e garantir resultados”. Já para Berbel (20II, p.29), as metodologias ativas "baseiam-se em formas de desenvolver o processo de aprender, utilizando experiências reais ou simuladas, visando às condições de solucionar, com sucesso, desafios advindos das atividades essenciais da prática social, em diferentes contextos”. A autora também informa que, a problematização utilizada nas metodologias ativas leva o estudante a buscar informações e a produzir conhecimento com a finalidade de encontrar soluções para os problemas. Desse modo, é possível que os estudantes desenvolvam, gradativamente, o seu pensamento crítico, criativo e reflexivo, bem como seus valores éticos.

A partir das definições apresentadas pelos autores citados, é possível ilustrar algumas características das metodologias ativas: Provocam o fazer e o pensar sobre o que se faz; Envolvem processos de aprendizagem flexíveis, interligados e híbridos; Visam ao protagonismo, à criatividade, à autonomia e à criticidade; Possuem um enfoque mais humanista, voltado aos valores éticos e ao aprender a ser; Envolvem conhecimentos, habilidades, competências e atitudes; Objetivam a apropriação, a produção de conhecimentos e a resolução de problemas; Valorizam a realidade e o contexto social e profissional do estudante; Contemplam atividades diversificadas para construção do conhecimento de forma individual, grupal e mediada.

A partir de suas características, evidencia-se que as metodologias ativas focam no protagonismo e na autonomia do discente e em uma educação mais centrada no ser humano, isto é, na capacidade humana de aprender e de se desenvolver levando em consideração a sua realidade, as suas perspectivas pessoais e profissionais, bem como as perspectivas dos outros, a partir de uma relação colaborativa e flexível, a qual pode ocorrer tanto presencialmente quanto à distância, por meio das tecnologias.

Nesse sentido, deve-se destacar que a Geografia, por ser uma ciência que analisa a construção social do espaço e, por conseguinte, as dinâmicas socioespaciais deve priorizar 
essa perspectiva dinâmica de ensino-aprendizagem. Durante séculos, a Geografia carrega a imagem de uma disciplina decorativa e enfadonha, resultado de um ensino enciclopédico baseado em concepções pedagógicas tradicionais de ensino-aprendizagem.

Mesmo com as renovações teórico-metodológicas da Geografia, o caráter enciclopédico ainda predomina nas aulas tanto do ensino básico, como no superior. A Geografia é marcada por uma histórica dicotomia físico/humano cujos conteúdos são trabalhados de forma enciclopédica, que, por sua vez, denotam um caráter decorativo e enfadonho à disciplina geográfica. Nessa perspectiva, o aluno não é posto como sujeito do seu próprio conhecimento, tão pouco problematizador das problemáticas socioespaciais.

Embora haja preponderância das metodologias tradicionais no ensino da Geografia, outras concepções de ensino ganham destaque dentro dessa área do conhecimento. Perspectivas atreladas à renovação da Geografia, que dialogam com concepções pedagógicas renovadas, que põem a problematização da realidade social dos discentes como cerne do processo de ensino-aprendizagem. Nessa perspectiva, Cavalcanti (1998) destaca que o ensino de geografia visa à aprendizagem ativa dos alunos, atribuindose grande importância a saberes, experiências, significados que os alunos já trazem para a sala incluindo, obviamente, os conceitos cotidianos. Assim, o ensino parte de uma perspectiva pedagógica tradicional, centrada no docente como possuidor do conhecimento enciclopédico e transmissor do mesmo, para compreensões que propõem a atuação dos discentes como agentes ativos no processo de desvendamento dos problemas sociais, problematização e ação frente a tais realidades.

Diante disso, o ensino da Geografia na EPT, tem como foco o desenvolvimento de competências e habilidades, com base na aprendizagem colaborativa e na interdisciplinaridade, caracterizando os princípios de atuação da Geografia na EPT e superando a histórica dicotomia físico/humano cujos conteúdos eram trabalhados de forma enciclopédica, que, por sua vez, denotam um caráter decorativo e enfadonho à disciplina geográfica. Nessa perspectiva, o aluno não é posto como sujeito do seu próprio conhecimento, tão pouco problematizador das problemáticas socioespaciais.

Portanto, frente a essa realidade imperante no contexto da educação geográfica brasileira, a proposição do ensino a partir de métodos ativos deve ocupar lugar de destaque, 
quando o assunto é o ensino de Geografia na EPT. É nesse sentido que as metodologias ativas podem ser consideradas como uma das estratégias de mediação de ensino de geografia na EPT. Tais metodologias podem permitir a construção do conhecimento significativo e contextualizado, por valorizarem o discente no núcleo de sua aprendizagem, com autonomia no próprio saber. Para Inocente; Tommasini; Castaman (2018, p. I):

\begin{abstract}
$\mathrm{O}$ processo de ensino e aprendizagem exige constantemente o aperfeiçoamento por parte dos professores em estratégias para a mediação de conteúdo. $\mathrm{Na}$ modalidade da Educação Profissional e Tecnológica (EPT) este aspecto não é diferente, já que necessita-se de métodos de ensino que permitam uma aprendizagem significativa e contextualizada, para a formação de competências para a vida pessoal e profissional do estudante. Nesta perspectiva, um dos caminhos são as metodologias ativas, as quais voltam-se para o protagonismo do estudante, sendo ele, o centro do aprendizado. Também favorecem a autonomia do estudante, estimulando a criatividade e preparando para a tomada de decisões no contexto em que ele vive. A partir do emprego das metodologias ativas, os estudantes tornam-se sujeitos históricos e assumem um papel ativo na aprendizagem, uma vez que compreende-se que este possui experiências e saberes que podem ser consideradas para a construção do conhecimento.
\end{abstract}

No contexto da Educação Profissional são ampliadas as possibilidades de reflexão crítica sobre a prática formativa dos sujeitos, a autoformação, visto que a formação integral destes seres é intrinsecamente ligada à compreensão de sua totalidade, isto é, ao pleno desenvolver de suas competências nas mais variadas dimensões.

De acordo com Pacheco; Pereira; Sobrinho (2010), essa modalidade da educação exige nos tempos atuais profissionais preparados para enfrentar os novos desafios relacionados às mudanças organizacionais, aos efeitos das inovações tecnológicas sobre as atividades de trabalho e as culturas profissionais, ao aumento das exigências na qualidade da produção e dos serviços - além da preparação para lidar com as implicações éticas de sua intervenção no mundo social, seja no tocante à função social da EPT, seja quanto a suas implicações ecológicas.

O ensino da Geografia na EPT, tem por missão formar profissionais cidadãos aptos não só para serem críticos reflexivos nas suas funções no mundo do trabalho, mas também na sua vida em geral, que é tecida por diversos tipos de relações sociais.

A Educação Profissional e Tecnológica enquanto modalidade de ensino exige a construção de conhecimentos que habilitem os estudantes a analisar, questionar e compreender o contexto em que estão inseridos. Além disso, é imperioso que estes desenvolvam capacidade investigativa diante da vida, de modo criativo e crítico; que identifiquem necessidades e oportunidades de melhorias para si, suas 
famílias e a sociedade na qual vivem e atuam como cidadãos. (INOCENTE; TOMMASINI; CASTAMAN, 2018, p. 5)

O professor de Geografia na Educação Profissional deve desenvolver uma prática pedagógica em que o aluno continue aprendendo, de forma autônoma e crítica, através de uma aprendizagem significativa oriunda dos métodos ativos e das metodologias ativas que o auxiliam através de recursos tecnológicos, pesquisa, aula invertida, atividades online, projetos integradores, artigos científicos, resenhas, seminários orientados, extensão, jogos, júri simulado, aulas de campo, debates críticos de conceitos, iniciação científica etc.

De acordo com Berbel (20II), as metodologias ativas além de desenvolver o processo de aprender, utilizam experiências reais ou simuladas, visando condições de solucionar com êxito os desafios advindos das atividades essenciais da prática social em diferentes contextos.

Considerando o princípio das Metodologias Ativas, o docente deve atuar na mediação de discussões; manter grupos de alunos focados em um problema ou questão específica; motivar alunos a se envolverem com as tarefas requeridas no processo de busca de solução; estimular o uso da função de pensar, observar, raciocinar e entender. Além disso, o planejamento das aulas de Geografia precisa basear-se no enfoque crítico para que a assimilação de novos conceitos possa associar-se a saberes já adquiridos pelos discentes, os saberes socialmente construídos. Conceitos claros, exemplos relacionados ao conhecimento prévio promoverão aprendizagem com significado. Um exemplo prático desta estratégia é associar o conceito de lugar aos seus ambientes conhecidos, vividos, como seu quarto, sua casa, sua rua, seu bairro e sua cidade.

Os tipos de materiais e linguagens de que se pode dispor são variados, como livros didáticos, paradidáticos, mapas, gráficos, imagens de satélite, literatura, música, poemas, fotografia, filme, videoclipe, jogos, aplicativos, slides, charges, cartuns, imagens, sala de aula invertida, para citar alguns. Cada um com características e especificidades que podem ser aproveitadas quando se objetiva fazer refletir sobre a ação humana na produção do espacial. É importante que o docente forneça as melhores e mais simples maneiras de auxiliar na compreensão dos conceitos e categorias de análise geográficos. 
Assim, à medida que o(a) discente percebe a Geografia presente em seu cotidiano, vai tornando-se cada vez mais capaz de desenvolver formas de aprendizado que possuam significado e aplicação prática. A capacidade de senso crítico se torna gradualmente mais intensa em relação aos textos que lê, às experiências e aos diálogos que trava e este fator nada mais é que o aprendizado acontecendo de forma mais simples e objetiva, adquirido por meio de suas próprias ações.

Diante disso, os benefícios das metodologias ativas no ensino da Geografia na EPT, para os discentes, são: maior engajamento, autonomia, participação e interesse por sentirem-se parte da própria construção do saber, pois prepara os estudantes para atender as demandas profissionais por meio das estratégias de ensino e desenvolve uma educação voltada para cidadania. Forma-se um profissional "capacitado" para determinada função, mas este consegue atrelar aquilo que está sendo ensinado ao contexto em que está inserido. Desse modo, torna-se um ser reflexivo, passando a ter voz ativa em seu aprendizado.

Por fim, as metodologias ativas fazem com que os alunos produzam o seu próprio conhecimento, estabelecendo elos entre o conceito apresentado pelo(a) docente e seu espaço de vivência, reconhecendo que o aprendizado é processual e que as formas de aprender vão se tornando elos com o que já se sabe num contexto em que o professor a se torna tutor(a) e os(as) alunos(as)pesquisadores e produtores de novos conhecimentos.

\section{RESULTADOS E DISCUSSÕES}

Esta revisão bibliográfica demonstra que existe um leque de opções em relação às metodologias ativas e discorre sobre importância da adoção de estratégias mais atualizadas para a educação das novas gerações que lidam com os mais diversos tipos de tecnologia digital e se relacionam por meio destas, demonstrando que o processo educativo passa a configurar-se como algo extremamente desafiador.

Diante disso, o processo de ensino-aprendizagem a partir de uma abordagem ativa vem recebendo relevante atenção, visto que tal fato poderá resultar em uma mudança do ensino tradicional para um ensino baseado em metodologias ativas, motivo de preocupação para alguns professores céticos em relação às inovações educacionais, embora já tenha atraído aqueles profissionais preocupados em buscar alternativas aos métodos de ensino tradicionais. Por isso, entende-se que, se a escola e o professor, não 
reconhecerem que as mudanças no mundo ocorrem e que necessitam buscar novas abordagens metodológicas, ressignificar a prática, tornar o processo educativo motivador, atrativo e prazeroso, permitindo ao aluno participar ativamente de seu aprendizado, não ocorrerá a superação do modelo de ensino tradicional e a possibilidade de abertura para novas práticas que propiciem uma aprendizagem efetiva e significativa. Isso tudo exige a necessidade de mudança na formação docente em relação aos recursos tecnológicos e metodologias ativas, e políticas públicas educacionais voltadas para a efetiva inserção das tecnologias na educação.

Isso ocorre porque muitos docentes não se sentem à vontade com as novas tecnologias, pois não tiveram acesso a ela em sua geração, e por isso as inovações e ferramentas educacionais soam como obstáculos. Além disso, a infraestrutura das escolas deve comportar rede de internet, computadores e demais recursos tecnológicos funcionando para que as atividades escolares dentro desse novo parâmetro possam ser colocadas em prática. Enfim, deve haver mudança na escola e principalmente nos professores.

\section{CONSIDERAÇÕES FINAIS}

Considerando a revisão bibliográfica apresentada neste artigo, infere-se que o uso das metodologias ativas no ensino de geografia no contexto da EPT contribui para a formação intelectual do discente, além de estimular a criatividade e o preparar para a tomada de decisões no contexto em que ele vive, o que traz benefícios para o desenvolvimento educativo humano na constituição de sua autonomia.

Entende-se que esta revisão trouxe alguns autores que tratam dos temas, porém ainda é um pequeno fragmento mediante a grandeza da temática estudada e sugere-se que as discussões possam ser ampliadas. Além disso, é sempre desejável que as metodologias ativas de ensino estejam em pauta de formas cada vez mais atualizadas e renovadas, na busca da construção do conhecimento crítico e reflexivo. Diante disso, entende-se que esta revisão bibliográfica refletiu sobre as contribuições das metodologias ativas no ensino de geografia na EPT de modo a desenvolver aprendizagens significativas e a formação para além dos muros físicos, tendo em vista todos os meios e recursos disponíveis hoje em dia. 


\section{REFERÊNCIAS}

BACICH, L. Ensino híbrido: personalização e tecnologia na educação. Porto Alegre: Bookman, 2015.

BACICH, L.; MORAN, J. Metodologias ativas para uma educação inovadora: uma abordagem teórico-prática. Porto Alegre: Penso, 2018.

BERBEL, N. As metodologias ativas e a promoção da autonomia dos estudantes. Semina: Ciências Sociais e Humanas, Londrina, v. 32, n. I, p. 25-40, jan./jun. 20II. Disponível em: $\langle$ http://www.proiac.uff.br/sites/default/files/documentos/berbel_2orI.pdf $\rangle$. Acessado em: 20 jun. 2021.

BRASIL. Ministério da Saúde. Resolução do Conselho Nacional de Saúde no 466 de 13 de junho de 2012. Disponível em:<http://conselho.saude.gov.br/ultimas_noticias/2013/o6_jun_I4_publicada_resolucao.ht ml>Acessado em: II jul. 2021.

BRASIL. Lei no 9.394, de 20 de dezembro de 1996. Estabelece as Diretrizes e Bases da Educação Nacional.

BRASIL. Resolução CNE/CEB no 6, de 20 de setembro de 2012. Define as Diretrizes Curriculares Nacionais para a Educação Profissional Técnica de Nível Médio. Disponível em: 〈http://mobile.cnte.org.br:8o8o/legislacao-externo/rest/lei/51/pdf.> Acessado em: 29 ago. 202I

DELORS, J. Educação: um Tesouro a Descobrir. UNESCO/ MEC: São Paulo: Cortez, 1999.

CAMARGO, F.; DAROS, T. A sala de aula inovadora: estratégias pedagógicas para fomentar o aprendizado ativo. Porto Alegre: Penso, 2018.

CAVALCANTI, L. de S. Geografia, escola e construção de conhecimentos. 4. ed. Campinas: Papirus, 1998.

HATTIE, J. Aprendizagem visível para professores: como maximizar o impacto da aprendizagem. Porto Alegre: Penso, 2017.

INOCENTE, Luciane; TOMASSINI, Angélica; CASTAMAN, Ana Sara. Metodologias Ativas na Educação Profissional e Tecnológica. Revista Educacional Interdisciplinar, v. 7, n. I, p. $\quad$ I-II, 2018. Disponível em: 〈https://seer.faccat.br/index.php/redin/article/view/ro82/664〉. Acessado em: o2 julh. 2021. 
KOSIK, Karel. Dialética do concreto. Trad. NEVES, Célia; TORÍBIO, Alderico. Rio de Janeiro: Paz e Terra, 2oio.

MATTAR, J. Metodologias ativas: para a educação presencial, blended e a distância. I $^{\underline{a}}$ ed. São Paulo: Artesanato Educacional, 2017.

MORAN, J. Metodologias ativas para uma aprendizagem mais profunda. In: BACICH, L.; MORAN, J. (Org.). Metodologias ativas para uma educação inovadora: uma abordagem teórico-prática. Porto Alegre: Penso, 2018.

MORÁN, J. Metodologias ativas e modelos híbridos na educação. Publicado em YAEGASHI, S. (Orgs), 2017. Disponível em: < http://www2.eca.usp.br/moran/wpcontent/uploads/2018/o3/Metodologias_Ativas.pdf.> Acessado em: 19 jul. 2021.

MORÁN, J. Mudando a educação com metodologias ativas. In: SOUZA, C. A.; MORALES, O. E. T. (orgs.), 2015. Disponível em: < http://www2.eca.usp.br/moran/wpcontent/uploads/2013/12/mudando_moran>. Acessado em: I9 ago. 202I.

PACHECO, Eliezer Moreira; PEREIRA, Luiz Augusto Caldas; DOMINGOS SOBRINHO, Moisés. Institutos Federais de Educação, Ciência e Tecnologia: limites e possibilidades. Revista Linhas Críticas, Brasília, v. ı6, n. 30, p. 71-88, jan./jun. 2010.

SILVA, B. Na nossa fita o laço é outro - O Design Thinking para ações colaborativas e participativas na escola. In: INSTITUTO CRESCER. Inovações na prática pedagógica: formação continuada de professores para competências de ensino no século XXI. Bárbara Szuparits (Org.) Crescer em Rede: Edição Especial - Metodologias Ativas. São Paulo, 2018.

VERGARA, Sylvia Constant. Projetos e relatórios de pesquisa em administração. 9 ed. São Paulo: Atlas, 2007.

VOLPATO, A. N; DIAS, S. R. Práticas inovadoras em metodologias ativas. Florianópolis: Contexto Digital, 2017. 